\title{
How Acceptable are Antiretrovirals for the Prevention of Sexually Transmitted HIV?: A Review of Research on the Acceptability of Oral Pre-exposure Prophylaxis and Treatment as Prevention
}

\author{
Ingrid Young $\cdot$ Lisa McDaid
}

Published online: 30 July 2013

(c) The Author(s) 2013. This article is published with open access at Springerlink.com

\begin{abstract}
Recent research has demonstrated how antiretrovirals (ARVs) could be effective in the prevention of sexually transmitted HIV. We review research on the acceptability of oral pre-exposure prophylaxis (PrEP) and treatment as prevention (TasP) for HIV prevention amongst potential users. We consider with whom, where and in what context this research has been conducted, how acceptability has been approached, and what research gaps remain. Findings from 33 studies show a lack of TasP research, PrEP studies which have focused largely on men who have sex with men (MSM) in a US context, and varied measures of acceptability. In order to identify when, where and for whom PrEP and TasP would be most appropriate and effective, research is needed in five areas: acceptability of TasP to people living with HIV; motivation for PrEP use and adherence; current perceptions and management of risk; the impact of broader social and structural factors; and consistent definition and operationalisation of acceptability which moves beyond adherence.
\end{abstract}

Resumen Investigaciones recientes han demostrado la forma en que los antirretrovirales pueden ser efectivos en la prevención del VIH. En este estudio se revisan trabajos sobre la aceptación de la profilaxis pre-exposición (PrEP, por sus siglas en inglés) y del tratamiento como prevención (TasP) para la prevención del VIH entre los potenciales usuarios. También se consideran con quién, dónde y en qué contexto esos trabajos de investigación han sido llevados a cabo, cómo se ha medido el nivel de aceptación y cuáles brechas de investigación permanecen abiertas. Los

I. Young $(\bowtie) \cdot$ L. McDaid

MRC/CSO Social and Public Health Sciences Unit, University

of Glasgow, 4 Lilybank Gardens, Glasgow G12 8RZ, UK

e-mail: i.young@sphsu.mrc.ac.uk resultados de los 33 estudios considerados evidencian una falta de investigación en el campo de TasP y PrEP. En el caso de estos últimos, los estudios existentes se han enfocado en hombres que tienen sexo con hombres en el contexto de los EEUU. Estos resultados también evidencian una falta de investigación en cuanto a las diferentes medidas de aceptación. Con el objetivo de identificar cuándo, dónde y para quién PrEP y TasP serían más apropiados y efectivos, se requieren estudios adicionales en cinco áreas: la exploración de la aceptabilidad de TasP para personas que viven con VIH; desde el punto de vista motivacional sobre el uso y adherencia a PrEP;; acerca de la forma actual en la que se percibe y se maneja el riesgo; el estudio de factores sociales y estructurales más amplios; y por último sobre la consistencia en la definición y sobre el fomento de la aceptabilidad más allá de la adherencia.

Keywords Pre-exposure prophylaxis - Treatment as prevention - Acceptability $\cdot$ HIV prevention

\section{Introduction}

The 30 years of the HIV epidemic have been marked by significant successes and failures in biomedical and behavioural research. While a cure or vaccine remain elusive, there have been significant advances in the clinical treatment of HIV [1], the prevention of mother to child transmission [2], and, to a lesser extent, in post-exposure prophylaxis (PEP) [3]. There have also been important community-based advocacy efforts and responses to HIV, including safer sex and risk reduction strategies, which form the basis of behavioural interventions as well as provide better understandings of the social contexts of the epidemic [4, 5]. However, the response to recent clinical 
trial results such as HPTN 052, Pre-exposure Prophylaxis Initiative (iPrEx) trial, and Partners in Prevention, which use antiretrovirals (ARVS) for prevention, has been significant. Hailed as 'the beginning of the end of AIDS' [6], these biomedical developments in HIV prevention provide exciting, if challenging, opportunities for HIV prevention.

Pre-exposure prophylaxis (PrEP) is the use of ARVs by HIV-negative individuals before potential exposure to HIV to prevent transmission. The iPrEx trial examined the efficacy of oral PrEP amongst men who have sex with men (MSM) and transgender women at high-risk of HIV, including HIV negative sexual partners in sero-discordant relationships. A sub-study of the iPrEx trial found that a daily dose of oral PrEP could reduce the risk of HIV transmission by up to $99 \%$ if adherence was high (taking seven tablets or more per week) [7]. In the United States (US), findings from iPrEx and other PrEP trials [8] resulted in the US Food and Drug Administration (FDA) approval of Truvada (emtricitabine/tenofovir disoproxil fumarate) for use as PrEP in July 2012 [9]. This was coupled with the release of Center for Disease Control and Prevention (CDC) interim guidelines on PrEP use for both MSM in January 2011 [10] and heterosexual men and women in serodiscordant relationships in August 2012 [11]. The guidelines advise initial screening for HIV and STIs, ongoing adherence and condom counselling, and 2-3 monthly follow up that includes regular screening for HIV and STIs. However, there have been mixed results from major PrEP trials; studies such as FEM-PrEP and VOICE recently failed to prove the effectiveness of PrEP as a result of poor participant adherence to the drug regime [12]. The US currently remains the only country where ARVs are licensed for use as PrEP. While some countries such as Latvia [13] have reported using PrEP, and HIV clinicians in South Africa have issued guidelines for off-label use for MSM, official implementation has been met with some caution. For instance, the British HIV Association (BHIVA) and British Association for Sexual Health and HIV (BASHH) issued a position statement calling for further research to confirm whether PrEP should be used as an effective HIV prevention option in the UK [14] and the European Medicines Agency (EMA) recently held a consultation on the clinical and non-clinical developments of PrEP in Europe [15].

Treatment as Prevention (TasP), already used effectively to prevent mother to child transmission [2], is also being advocated as a means to manage and reduce sexual transmission of HIV. The HPTN 052 trial found that starting HIV-positive sexual partners on ARVs early (i.e. before their CD4 count dropped below the levels of $200-350$ cells $/ \mu \mathrm{L}$ advised in international guidelines for treatment initiation at the time of the trial) resulted in a $96 \%$ reduction in HIV transmission amongst heterosexual serodiscordant couples [16]. The results from HPTN 052 have led to changes in treatment guidelines in the US and a number of European countries such as the UK, France and Germany $[13,17,18]$. More recently, the World Health Organisation has called for HIV treatment to be started at 500 cells $/ \mu \mathrm{L}$ [19]. These changes highlight how TasP is rapidly establishing itself as a clinically sanctioned method of HIV prevention [20]. However, although hailed as 'proof of concept' in relation to ARVs preventing sexual transmission, how TasP should be implemented on population-wide level is less clear and has raised a number of practical and ethical issues [21]. The effectiveness of TasP will rely on the early diagnosis and retention in care of HIV positive individuals, who often experience multiple barriers to accessing services and treatment [22]. This approach also raises the question of whether individuals living with HIV should be asked to start treatment in order to prevent transmission to others, rather than in relation to their clinical needs [23]. These issues need to be addressed before TasP is rolled out at a population level.

Recent findings from PrEP and TasP trials are situated in a longer history of how ARVs are part of and affect HIV prevention. The introduction of highly active antiretroviral therapy (HAART) in the mid-1990s raised concerns that optimism as a result of new HIV treatment might result in an increase in sexual risk behaviour. Research into HIV treatment optimism did not find a consistent association between HIV optimism and high-risk sexual behaviour $[24,25]$. More recently, a review of treatment-related optimistic beliefs and risk of HIV transmission found mixed results. While quantitative studies demonstrated a link between optimism and risk of transmission, the review found that inconsistent measures and qualitative findings raise questions about this association and calls for a more comprehensive examination of HIV treatment optimism issues [26]. In 2008, the 'Swiss Statement' further complicated HIV prevention messages by stating that people living with HIV who are on treatment, have an viral load that has been undetectable for at least 6 months and do not have an STI are not sexually infectious [27]. Research about issues raised by the Swiss Statement revealed that sexual decision making in relation to HIV prevention was not based solely on calculations of risk, but also on socioeconomic factors [28] and emotional and relationship priorities [29]. These findings suggest that the way in which people understand biomedical prevention methods and incorporate them into the context of their everyday lives will be critical to of the management of HIV-related risks.

There is considerable debate about the ways in which the PrEP and TasP should (and will) be introduced as HIV prevention options. Nguyen et al. [23] have expressed anxieties that ARV prevention will replace behavioural interventions (and the necessary funding of the latter); Padian et al. [1] have called for combination prevention, recognizing the continued need to manage and support behaviour change 
strategies [30]; and the VOICE trial findings have resulted in calls for improved understandings of what social, cultural and other factors affect adherence [31]. Indeed, rather than separating biomedical from behavioural interventions, a number of authors have characterised PrEP and TasP as biobehavioural, pointing to how individuals will have to modify their behaviour to take the medication [32, 33]. As in the case of HIV treatment optimism, responses to the Swiss Statement, and the non-adherence to PrEP by participants in the VOICE trial, people's actual use (or non-use) of PrEP or TasP will have a significant impact on their effectiveness in preventing the sexual transmission of HIV. We need, therefore, to better understand if, how and in what contexts, PrEP and TasP will be acceptable to people seeking to prevent the sexual transmission of HIV.

While PrEP and TasP may reflect different programmatic approaches to the prevention of sexual transmission of HIV - an individual approach to PrEP in contrast to a potential population-wide approach for TasP-there is considerable overlap in how each intervention may be managed at an individual level and how they may or may not be acceptable to trial participants, potential end users and/or their sexual partners. Research on the acceptability of contraception, perhaps the closest comparator for biomedical-based interventions in sexual health, considers acceptability to be the voluntary, sustained use of a product in the context of alternatives [34]. With regards to oral and microbicide-based PrEP in clinical trials, Mensch and colleagues point out that there is little agreement in the literature on how acceptability is defined and measured. They suggest that acceptability should be judged in relation to adherence to the medication, and consider elements such as product attributes, dosing regimen, deliver mechanisms, but also partner's attitudes and the effects of the product on sexual encounters [35]. Similarly, Golub et al. [33] describe the need to support individuals in their uptake, use and risk-reduction strategies, encouraging them to make rational choices about their sexual health. In this review, we assess the literature on the acceptability of oral PrEP and TasP for the prevention of sexually transmitted HIV amongst potential users. We consider with whom, where and in what context this research has been conducted, how acceptability has been approached, and what research gaps remain.

\section{Methods}

Five major databases (Medline, Psychinfo, Web of Science, Embase and Global Health) were initially searched using the terms in Box 1. Subsequent searches were conducted on PubMed to update the initial search. Articles were included if they:
- examined acceptability of oral PrEP and/or TasP as HIV prevention options in the context of sexual transmission;

- described primary data collection with current or potential oral PrEP or TasP users (including empirical studies, embedded studies in larger RCTs and process evaluations);

- were published in English; and

- were published between January 2008 (in order to capture research related to recent ARV developments) up to December 2012.

The earliest study identified in our search on the use of oral ARV-based technologies for the prevention of sexually transmitted HIV was published in 2008 and reflects the startpoint for this review. Editorials or comment pieces were excluded as they did not include primary data collection. Of a total of 90 articles found, 33 met the inclusion criteria. These articles were all sourced from peer-reviewed journals. A number of conference abstracts were identified, but were excluded due to insufficient information about how acceptability was measured and limited information on findings. Formal quality appraisal of the publications was not undertaken as the aim of this review was to establish a broad overview of research available, including how acceptability was assessed, where studies have been conducted, and what the key findings were in relation to acceptability. Assessment was made of individual articles, even when multiple articles were from the same study. The first author identified key characteristics of each study in accordance with STROBE

Box 1 Search terms used

\begin{tabular}{ll}
\hline MESH terms used & Free text search terms used \\
\hline 'HIV infections' & HIV \\
'HIV infections/ & 'Human immunodeficiency virus' \\
prevention \& control*' & 'human-immunodeficiency-virus' \\
'Antiretroviral therapy, & HIV prevention \\
highly active' & TAP \\
'Patient acceptance & TASP \\
of health care' & 'Treatment as prevention' \\
& 'treatment-as-prevention' \\
& PREP \\
& 'pre-exposure prophylaxis' \\
& 'pre exposure prophylaxis' \\
& 'preexposure prophylaxis' \\
& 'Highly active antiretroviral treatment' \\
& HAART \\
& 'treatment outcome' \\
& feasib* \\
acceptab* & adoption \\
attitude*
\end{tabular}


(Strengthening the Reporting of Observational studies in Epidemiology) checklist [36]. This specifically included: participants; setting; type of intervention; study aims; study design and methods; study size; measures of acceptability; key results; and interpretations. The second author reviewed the identification and organisation of key characteristics and verified these findings.

\section{Results}

Of the 33 articles and reports in our review, 30 addressed the acceptability of PrEP, reflecting 27 separate studies, and three addressed the acceptability of TasP. A detailed overview of each publication is included in Table 1.

\section{PrEP Studies}

Eight articles were based on non-clinical research embedded in six separate larger clinical PrEP trials. Three articles, from two trials, focused on heterosexual women's experiences in serodiscordant relationships in African countries [37-39], with an additional article focusing on heterosexual women's experiences in South Africa, Uganda and the US [40]. Two articles from one trial in Kenya explored acceptability and willingness amongst MSM [41, 42] while one article focused on MSM in the US [43]. The eighth article described the identification, development and implementation of procedures within the iPrEx study that intended to improve product use and selfreport across all the trial sites [44].

Twenty-two PrEP articles were from non-clinical trial research and the majority of these focused on MSM. Ten articles, from nine studies, were with MSM in the US [45-54]. Other articles focusing on MSM included research from the UK [55], Canada [56], France [57], Australia [58, 59], Thailand [60], and China [61, 62]. Galea et al. [63] focused on MSM, female sex workers, and transgendered people in South America (Peru), as did Eisingerich et al. [64], who also included intravenous drug users, serodiscordant couples and young women in Ukraine, India and four countries in Africa. Only two (US) studies explored attitudes towards PrEP amongst heterosexual men and women $[65,66]$. The majority of these studies focused on daily oral PrEP, with only five exploring attitudes towards intermittent, or in some cases topical, PrEP use [57, 59, 60, 63, 64] (Table 2).

\section{TasP Studies}

Two of the three TasP studies were conducted in the US $[67,68]$, and the other was Australian [69]. One explored acceptability of TasP amongst people living with HIV but not currently on treatment in Seattle, Washington [67]. A second article examined beliefs around undetectable viral loads and STI acquisition amongst men, women and transgendered people living with HIV in Atlanta, Georgia [68]. A third study explored attitudes towards ARVs, HIV treatment and ARV-based prevention amongst both HIVpositive and HIV-negative participants in Australia [69].

\section{Measures of Acceptability}

The articles used a range of approaches to assess and/or measure acceptability of either PrEP or TasP. PrEP acceptability research embedded within RCTs used individual adherence rates as a measure of acceptability. For those PrEP studies outside of clinical research, the measurement and/or assessment of acceptability varied greatly. Four articles reported on willingness to use PrEP [45, 54-56]. Eight articles reported further on multiple attitudinal issues such as willingness to take PrEP, HIV prevention, access to PrEP, perceptions of personal risk, stigma and continued condom use $[48,49,51,57,58,61,62,64,65]$. Two of these reported on scenarios or conjoint analysis [51,64]. Qualitative-based articles were less specific about particular questions, but reported a wide range of acceptability issues, including: perceptions of transmission risk; feelings about safer sex; information desired about PrEP; concerns with cost, access, side-effects and regular testing [46, 47, 53, 63]. Measurements of TasP acceptability were similar in variation. Two studies reported on interest in TasP $[67,68]$. One study reported on scepticism that reduced viral loads would prevent HIV, as well as concerns about side-effects, ease of taking medication and stigma-related issues [69].

Although two studies [53, 66] highlighted the importance of how information regarding biomedical interventions is framed and delivered to communities, few of the articles reported on how they explained PrEP or TasP efficacy to participants. Five articles presented PrEP efficacy rates to participants of $80 \%$ [48], $90 \%$ [46, 47], or a range of scenarios between 75 and $95 \%$ efficacy [63], and 50 and $75 \%$ efficacy [66]. However, the majority of studies did not specify efficacy of PrEP to participants, or did not report doing so. Similarly, TasP studies did not present precise information about the efficacy of the intervention. Participants in the study by Dombrowski et al. [67] were told that they were less likely to transmit HIV while on medication, but that no one knew for certain. Two more TasP studies did not present participants with information about TasP but asked a range of questions to gauge beliefs about HIV medicines and infectiousness [68, 69].

Adherence as Acceptability

Three of the PrEP studies in clinical trials reported high levels of adherence to daily pills, ranging from 82 to 


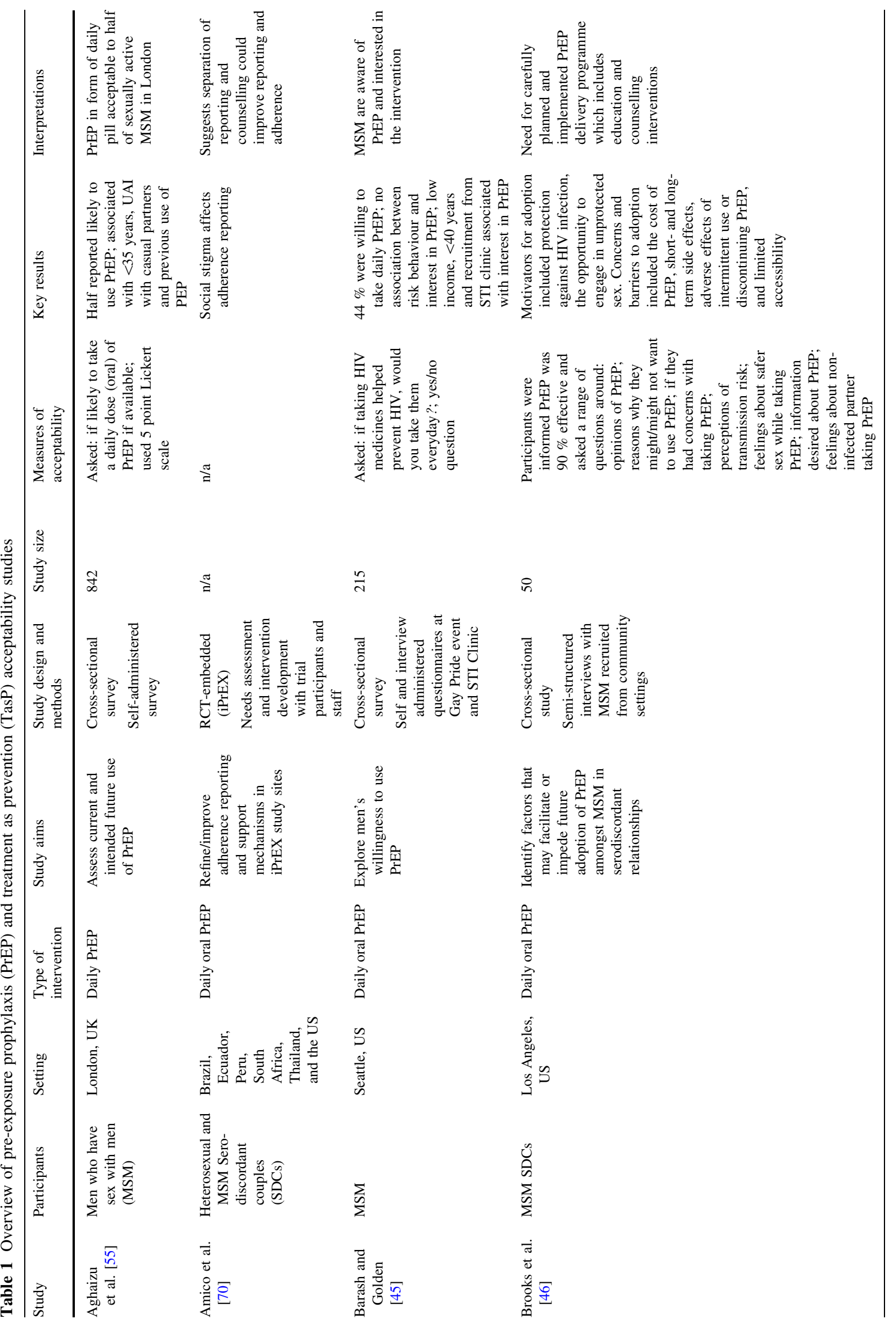




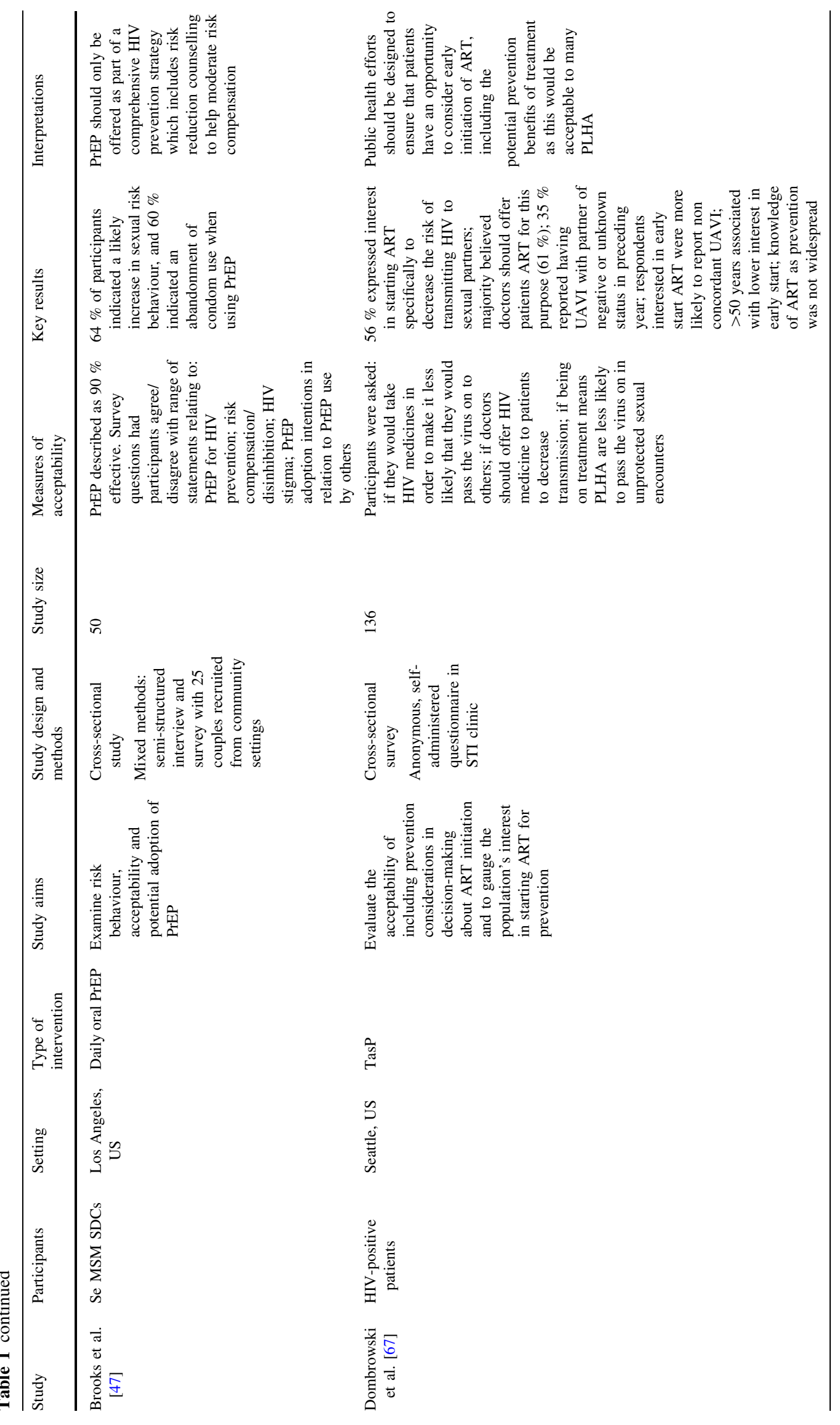




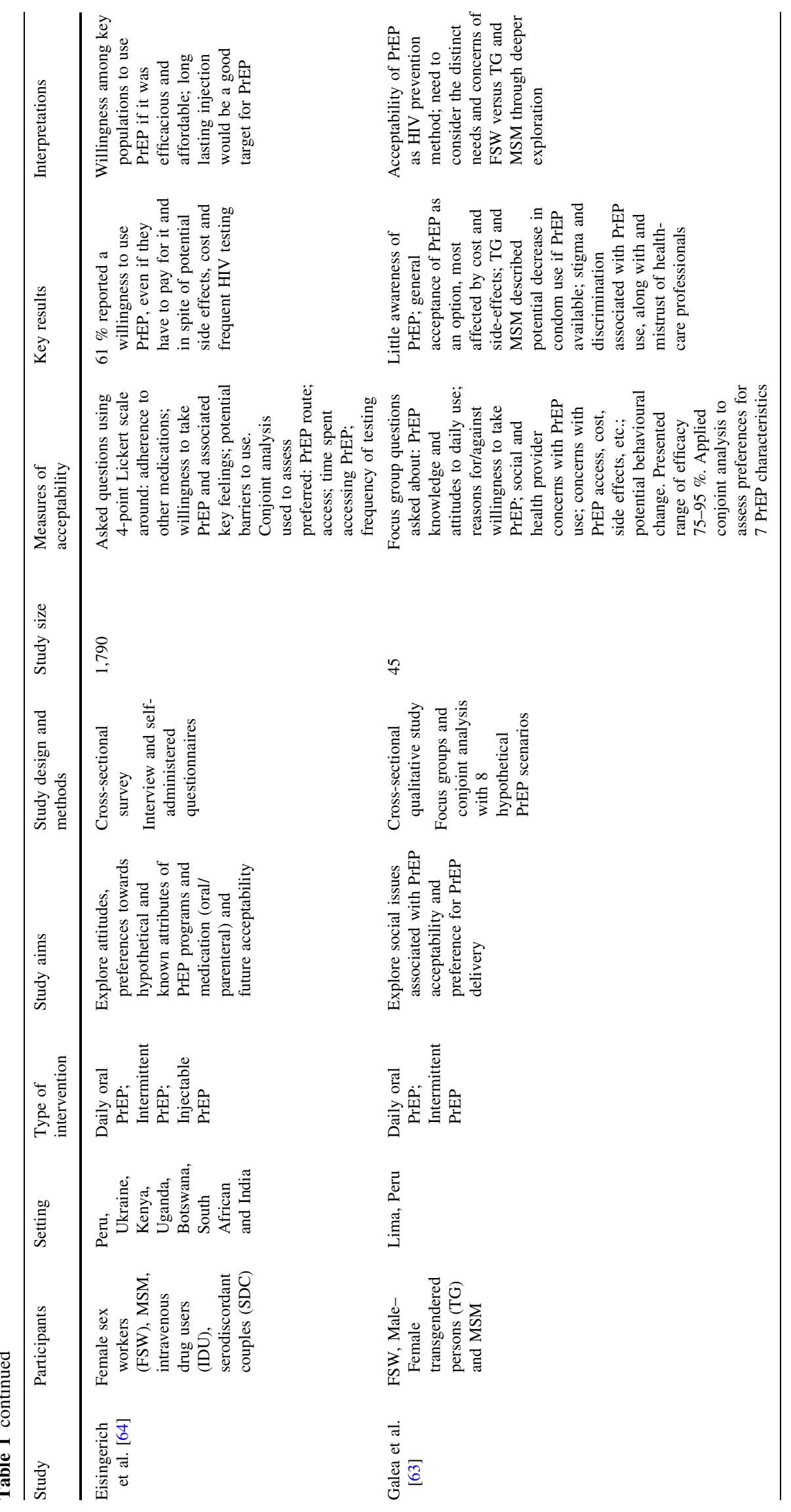




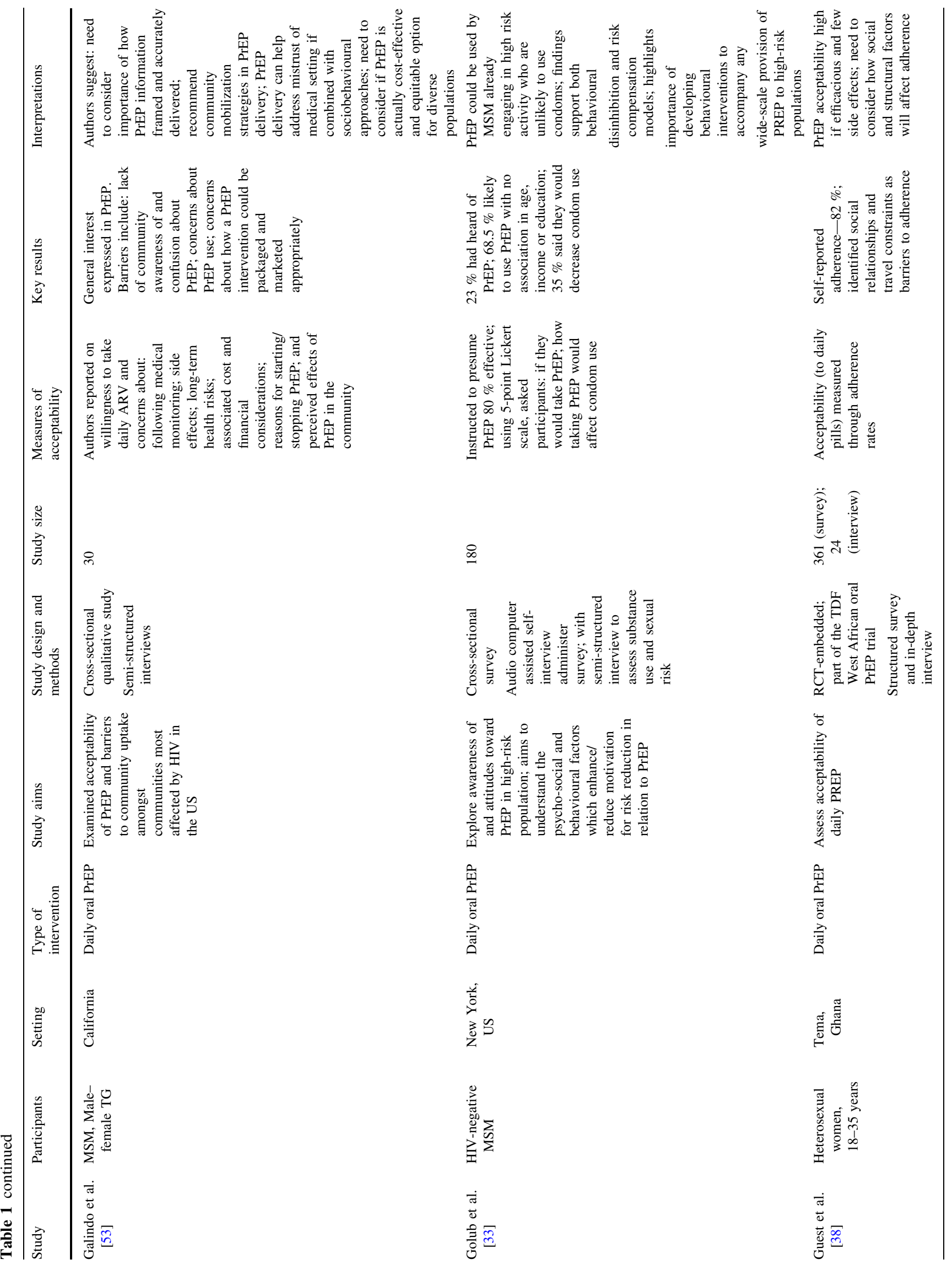




\begin{tabular}{|c|c|c|c|}
\hline & 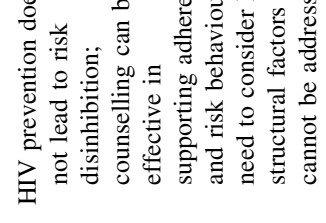 & 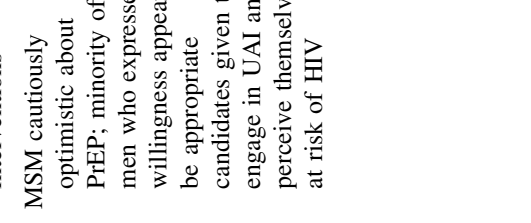 & 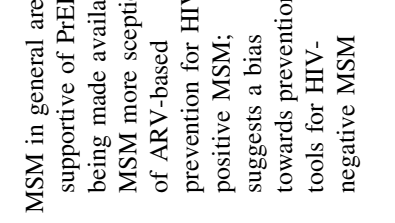 \\
\hline & 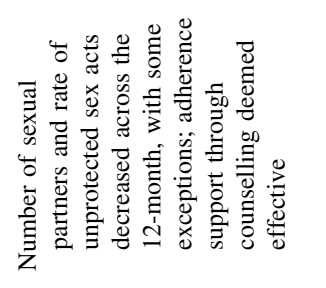 & 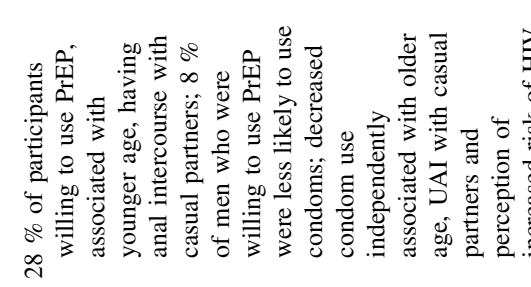 & 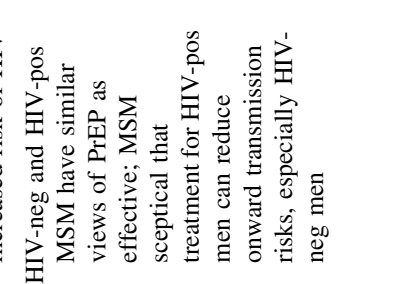 \\
\hline 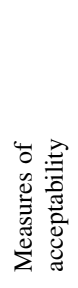 & 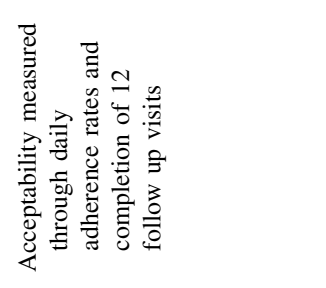 & 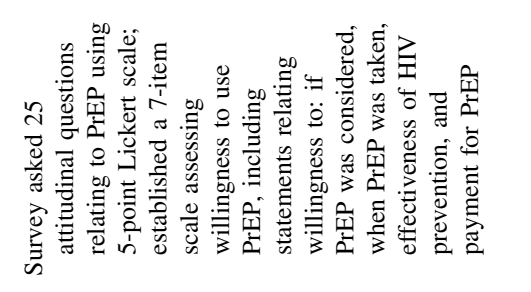 & 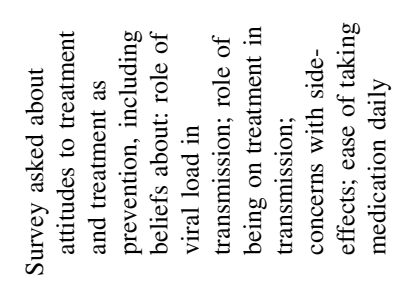 \\
\hline 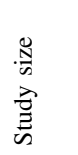 & 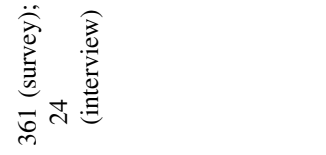 & $\stackrel{\vec{\sigma}}{=}$ & 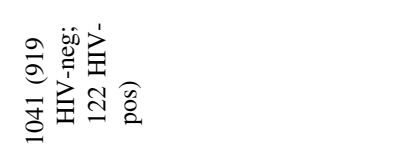 \\
\hline 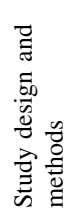 & 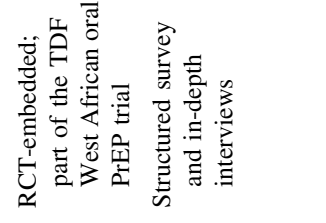 & 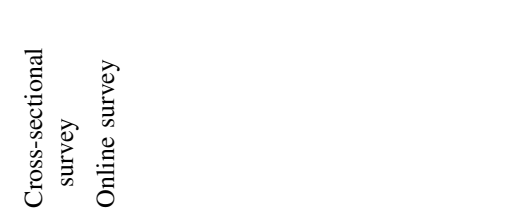 & 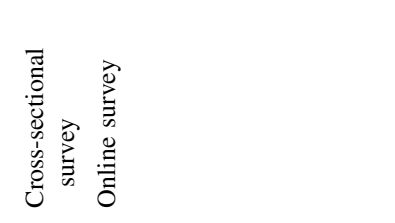 \\
\hline 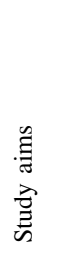 & 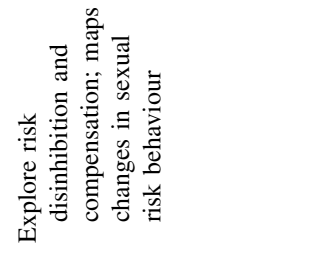 & 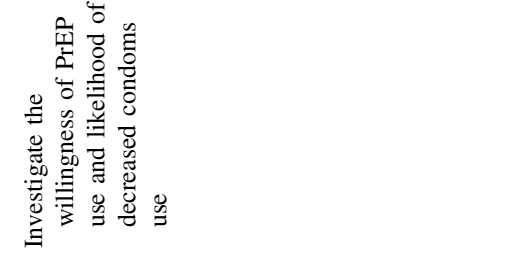 & 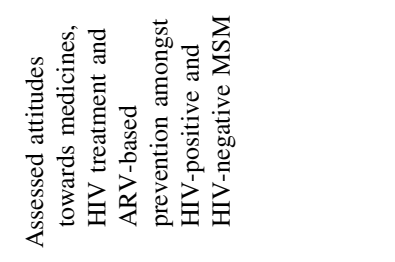 \\
\hline 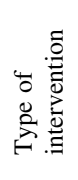 & 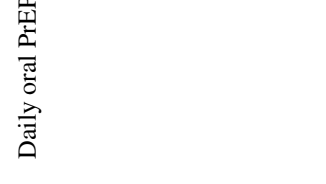 & 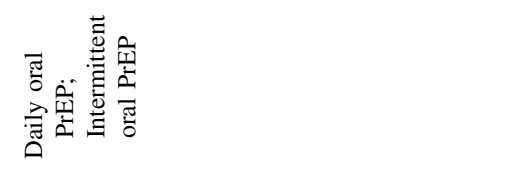 & 耪 \\
\hline $\begin{array}{l}\text { 总 } \\
\text { 童 }\end{array}$ & 焉 & 嵒 & 震 \\
\hline & 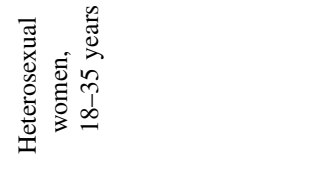 & $\frac{\sum_{\overline{2}}}{\mathrm{n}}$ & $\sum_{\sum}^{n}$ \\
\hline 힐 & 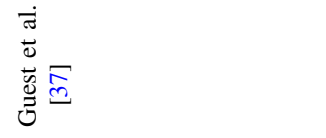 & 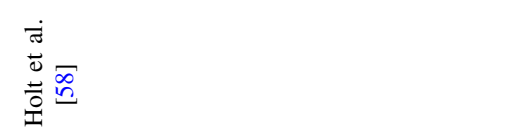 & 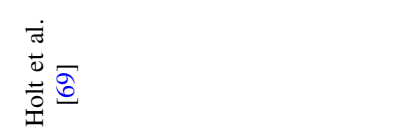 \\
\hline
\end{tabular}




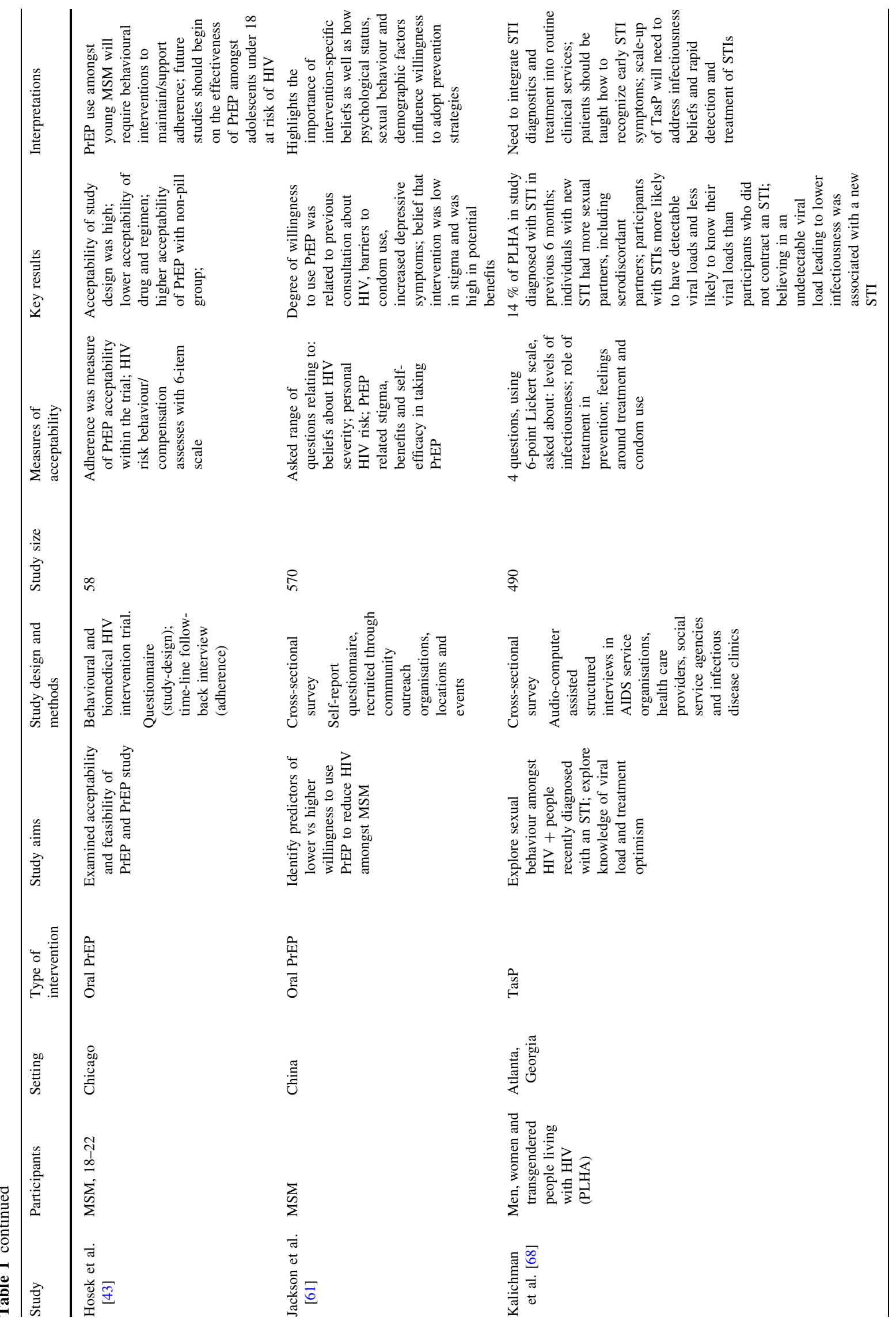




\begin{tabular}{|c|c|c|c|}
\hline & 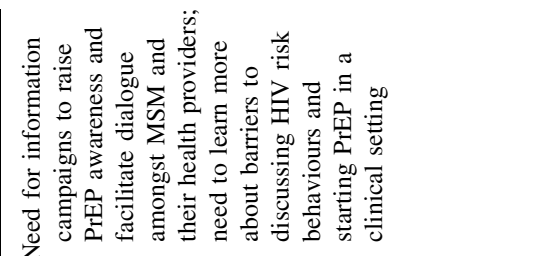 & 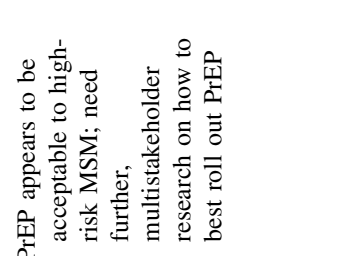 & 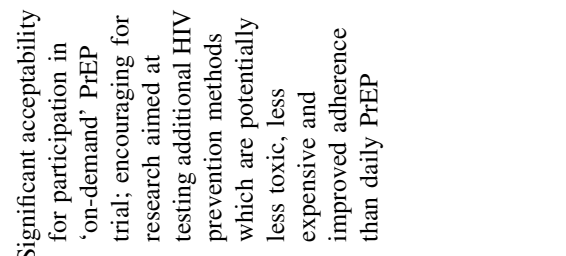 \\
\hline & 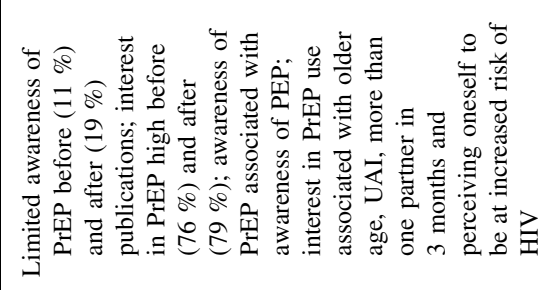 & 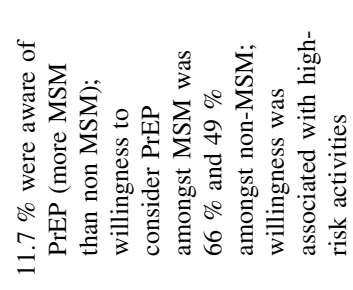 & 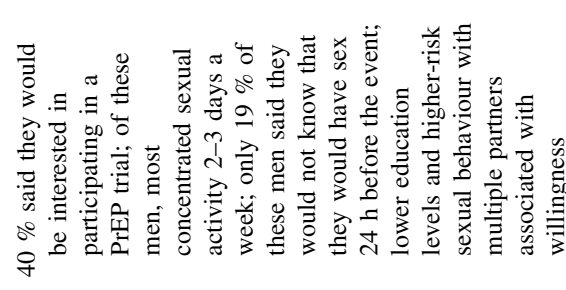 \\
\hline 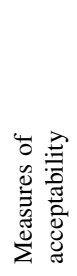 & 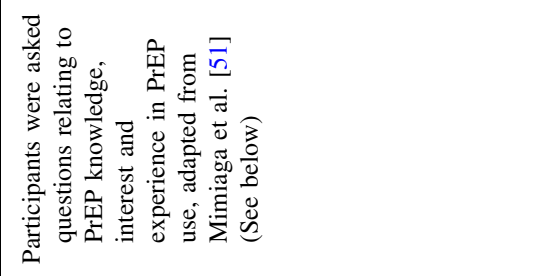 & 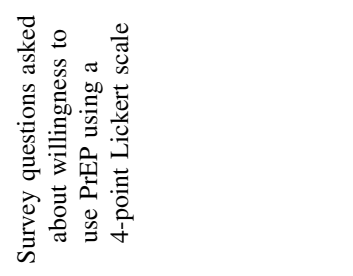 & 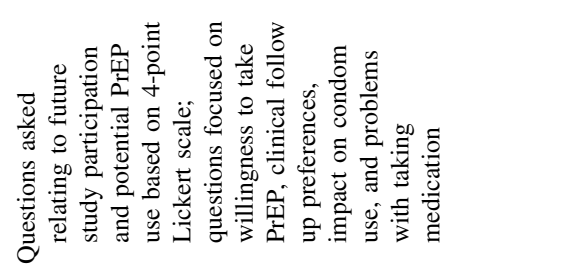 \\
\hline & 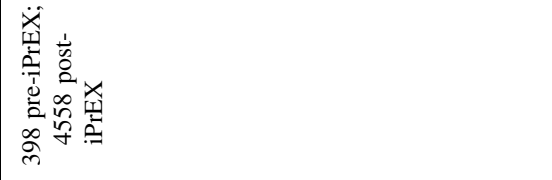 & 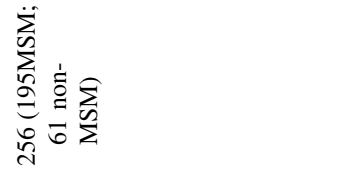 & $\hat{n}$ \\
\hline 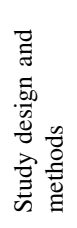 & 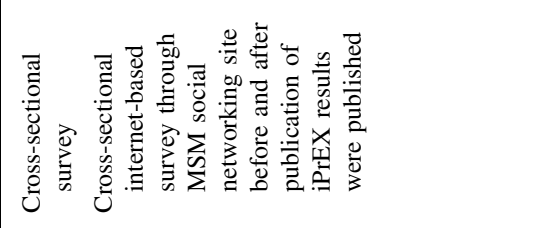 & 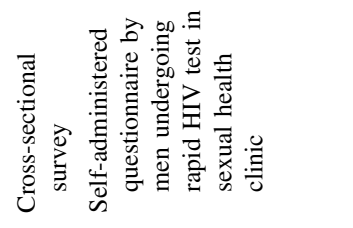 & 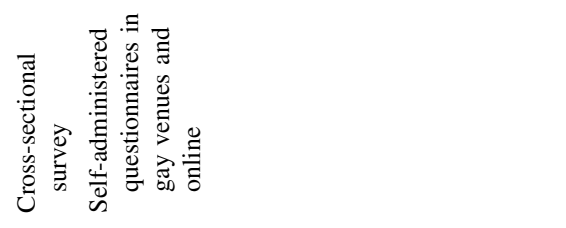 \\
\hline 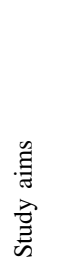 & 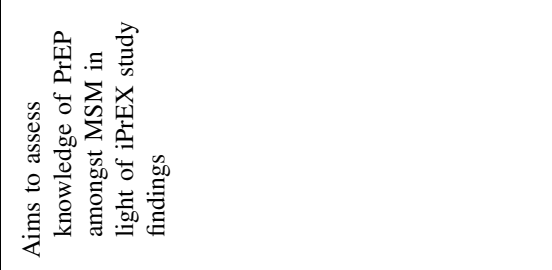 & 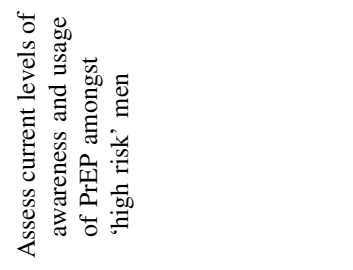 & 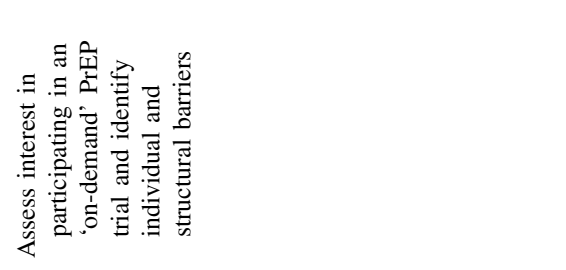 \\
\hline 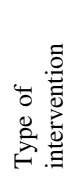 & 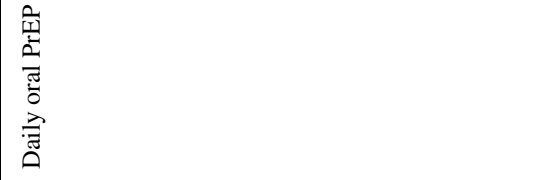 & 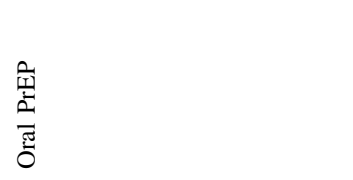 & 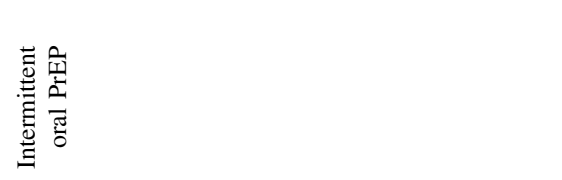 \\
\hline & 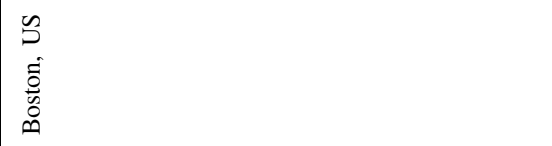 & 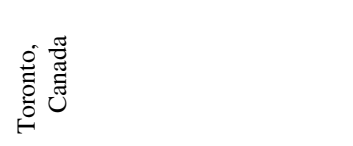 & 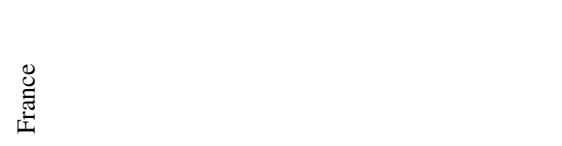 \\
\hline & $\sum_{\sum}^{n}$ & 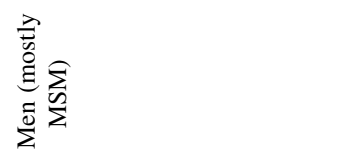 & $\sum_{\sum}^{\infty}$ \\
\hline 굴 & 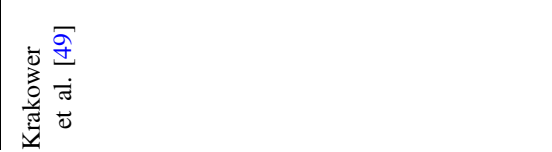 & 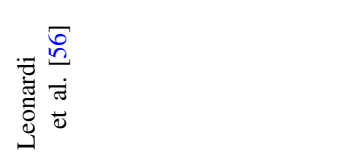 & 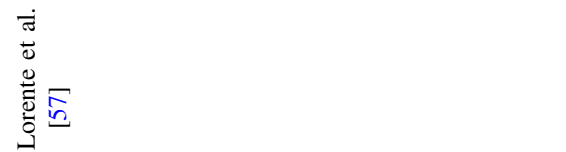 \\
\hline
\end{tabular}




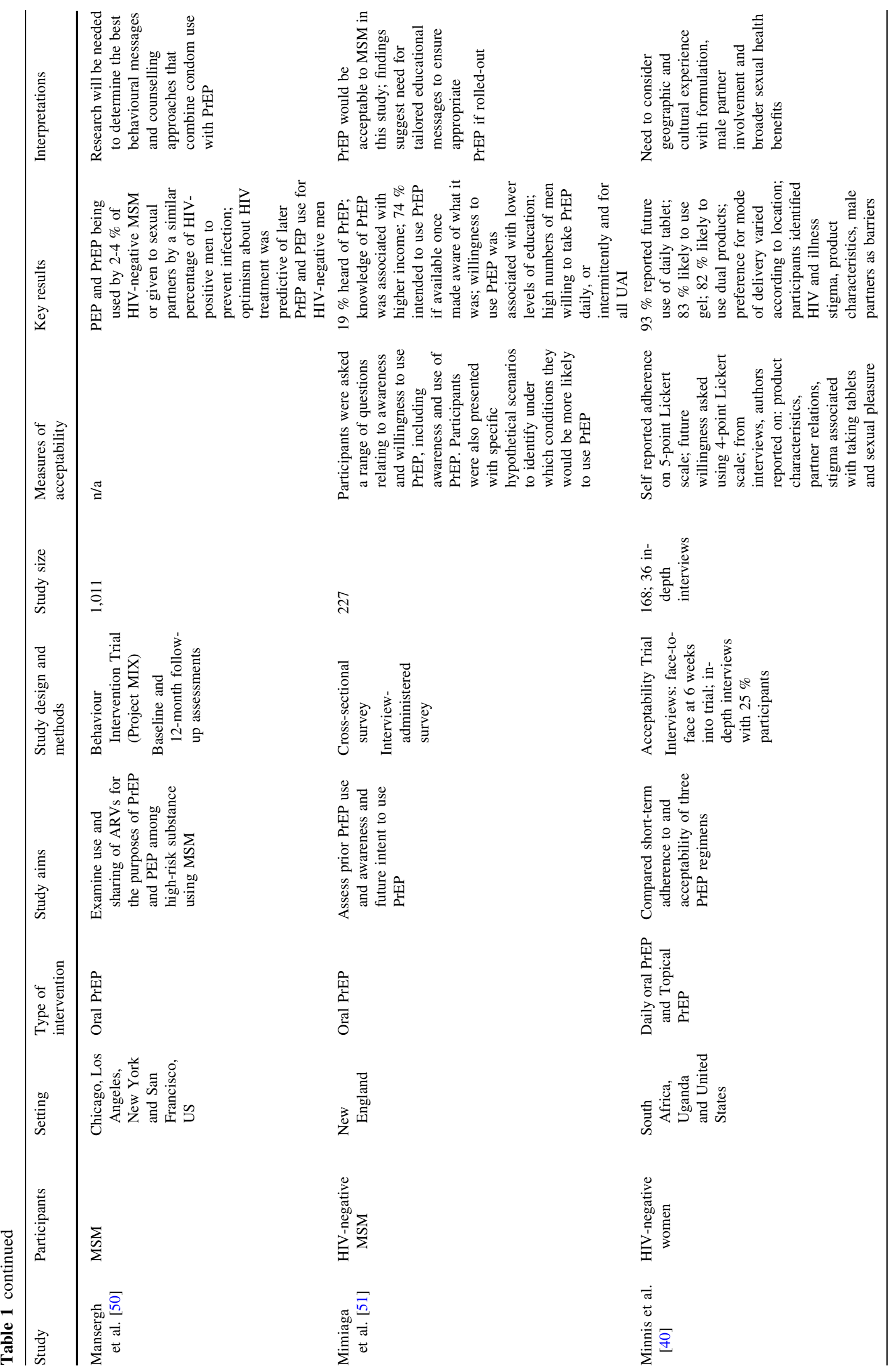




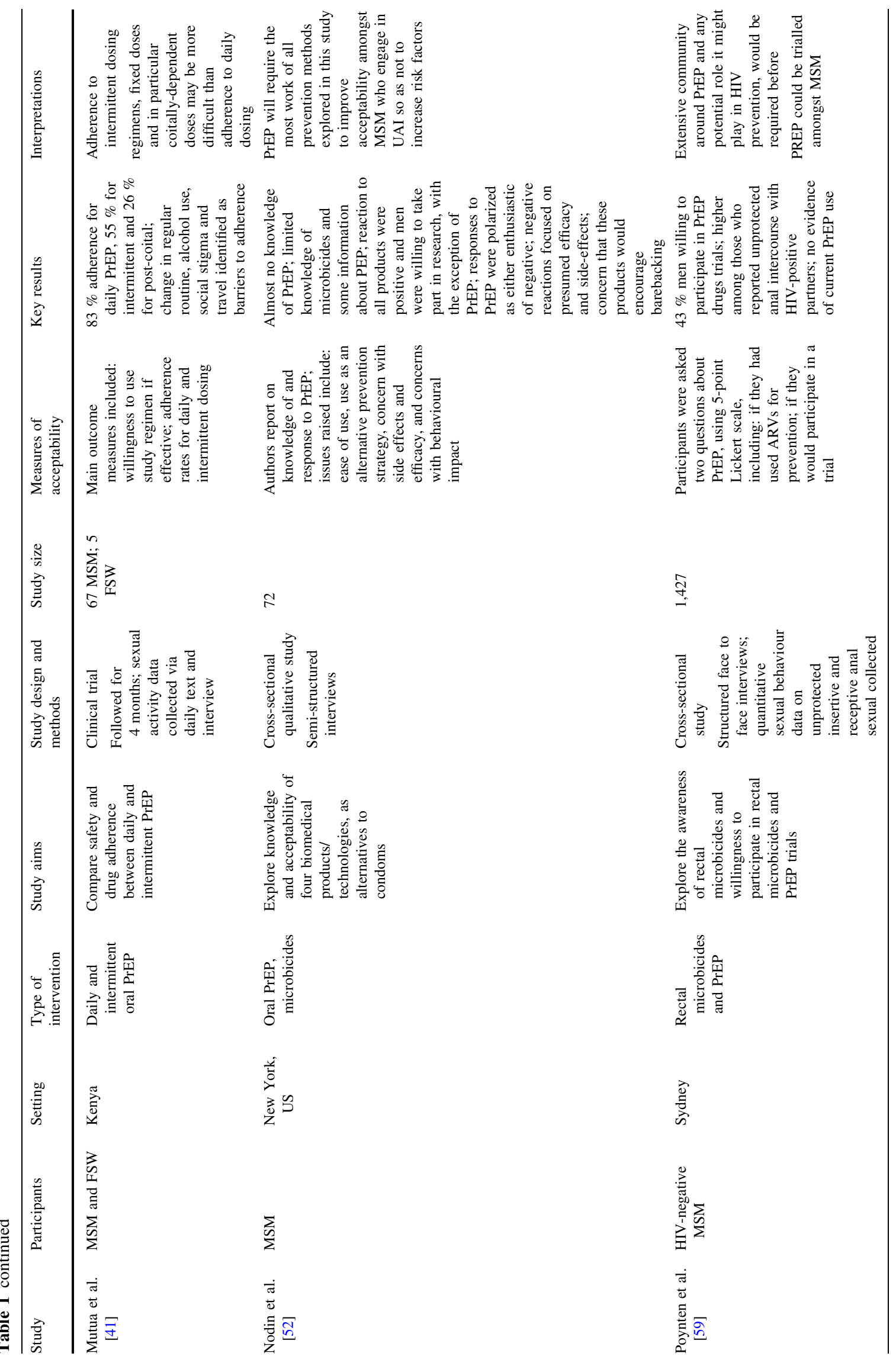




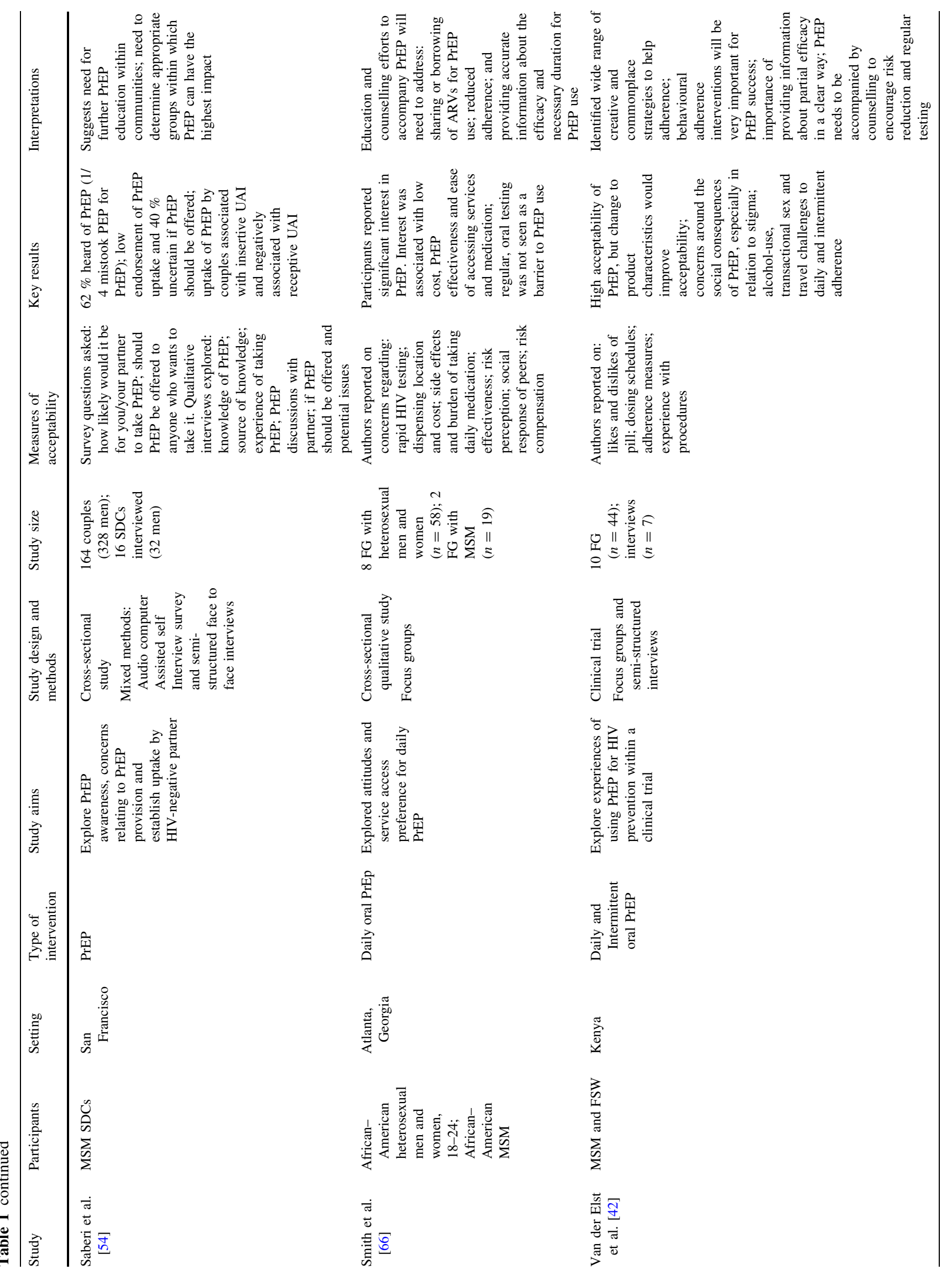




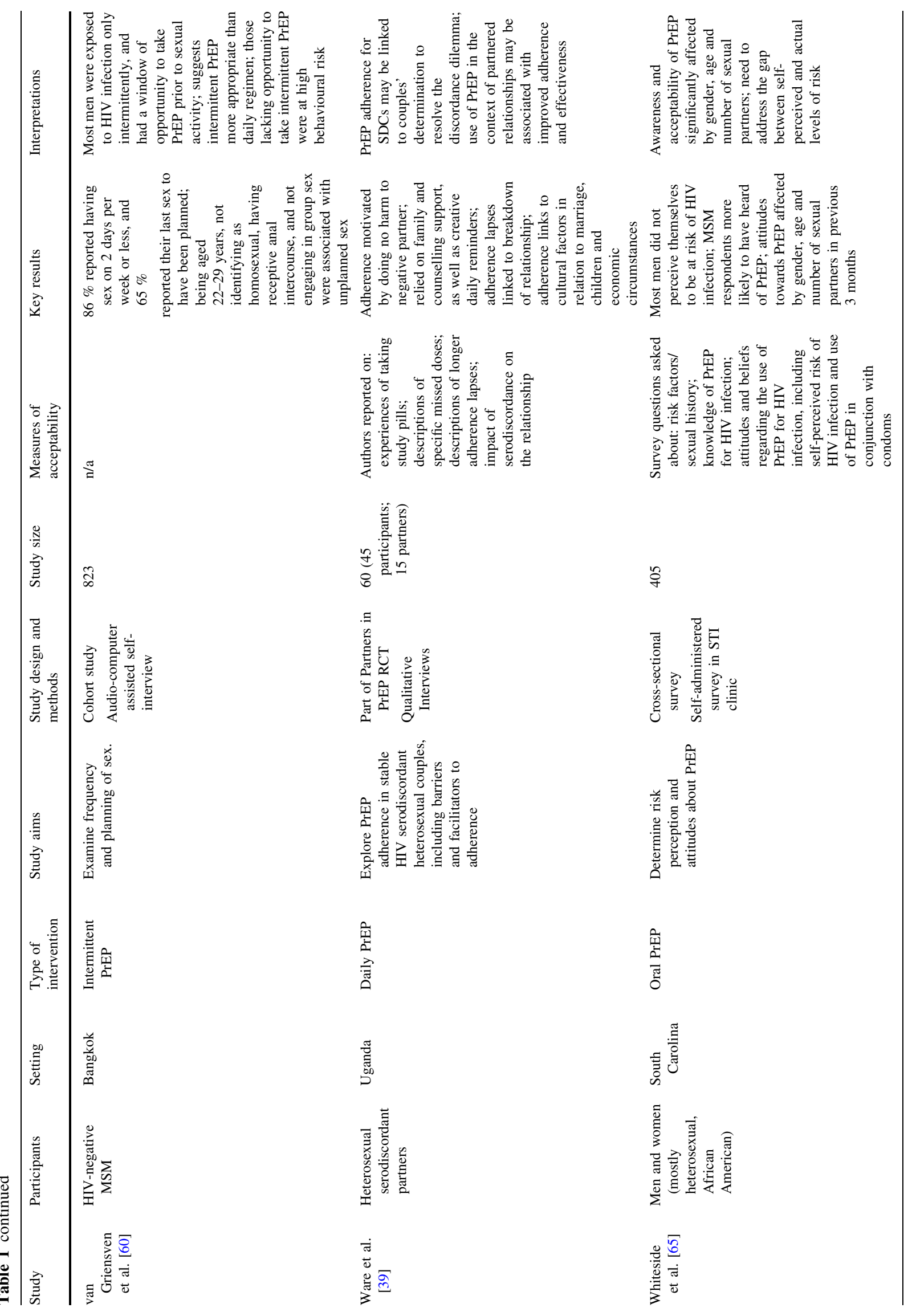




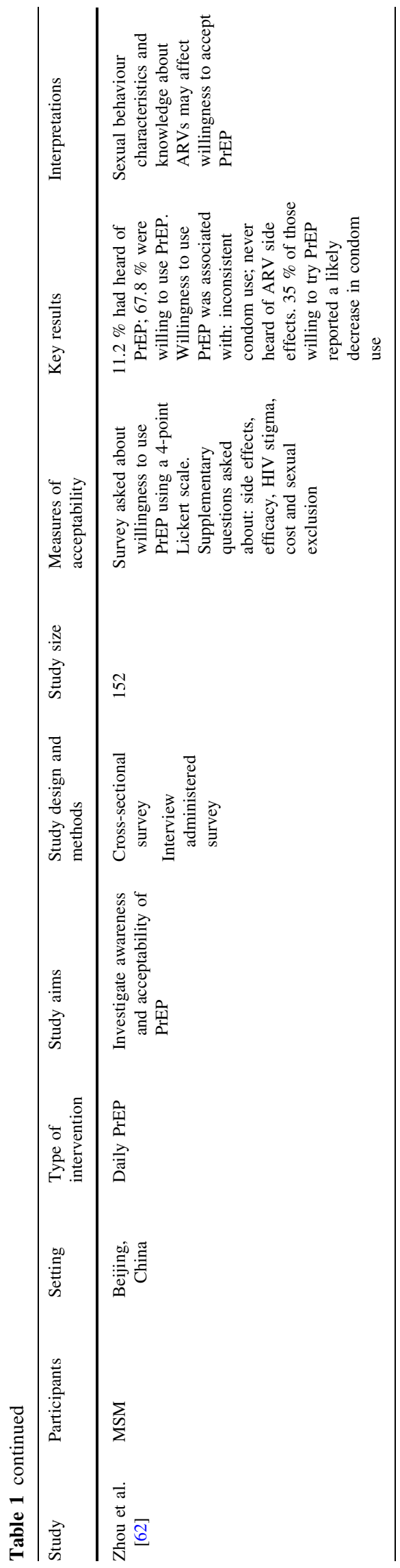

$93 \%$ [38, 40, 42]. However, Amico et al. [70] noted discrepancies between self-report and actual adherence rates in their needs assessment of adherence reporting in the iPrEx trial. They described the way social stigma played an important role in how adherence was reported; the combination of pill monitoring and adherence counselling did not provide the space for participants to explore their adherence difficulties without feeling judged. In the Partners in Prevention trial in Uganda, participants' adherence was significantly affected by a desire to do no harm to their partner, and by the marital, family and economic circumstances of the positive partner [39].

\section{Willingness as Acceptability}

Studies that were not part of larger PrEP clinical research trials reported limited knowledge of PrEP, ranging from $11 \%$ [56] to $23 \%$ [33]. One study [54] did report $62 \%$ of participants had heard of PrEP, although one-quarter mistook PEP for PrEP. Levels of willingness to use PrEP ranged from $28 \%$ [58] to $80 \%$ [47]; eight out of eleven studies offering numerical findings reported willingness levels of $50 \%$ or more $[47-49,51,55,56,62,64]$. All of the studies reporting willingness in this way focused on MSM. Factors associated with willingness to use PrEP were mixed and there were no strong similarities across the studies. Greater willingness was associated in some studies with lower levels of education [51] and younger age [45, 55]. Four studies reported an association between willingness to take PrEP and unprotected anal intercourse (UAI) [49, 54-56], while Zhou et al. [62] reported an association between PrEP willingness and inconsistent condom use. However, Golub et al. [33] found no association between willingness and age, income or education, and Barash and Golden [45] found no association between willingness and risk behaviour. Holt et al. [58] were unusual in reporting low rates of willingness in their Australian study. Factors associated with willingness in this study were younger age, UAI with casual partners, and increased risk-perceptions. Despite relatively high willingness to take PrEP in most studies, anxieties around medication sideeffects were also commonly reported [46, 52, 63, 64]. Only two studies explored associations with PEP experience and none explored knowledge of and/or experience with earlier generations of ARVs [50, 55].

In the TasP studies, knowledge of this prevention method was low. In one, $56 \%$ of HIV positive participants expressed an interest in starting treatment early, while $61 \%$ of participants felt doctors should offer early ART as an option to prevent onward HIV transmission [67]. Interest in starting treatment in this study was associated with being younger than 50. Holt et al. [69] reported that 
Table 2 Breakdown of PrEP articles by participants and setting

\author{
${ }^{a}$ Galindo et al. [53] also \\ include TG participants \\ b Galea et al. [63] also include \\ TG and female sex worker \\ participants \\ ${ }^{c}$ Smith et al. [66] also include \\ small number of MSM \\ participants
}

\begin{tabular}{|c|c|c|c|}
\hline Participants & Setting & $\begin{array}{l}\text { No. of } \\
\text { articles }\end{array}$ & $\begin{array}{l}\text { No. of } \\
\text { studies }\end{array}$ \\
\hline \multicolumn{4}{|l|}{ Clinical trial PrEP research } \\
\hline Heterosexual women & Africa & 4 & 3 \\
\hline Men who have sex with men (MSM) & Africa & 2 & 1 \\
\hline MSM & US & 1 & 1 \\
\hline Heterosexual and MSM & Multi-country & 1 & 1 \\
\hline Total & & 8 & 6 \\
\hline \multicolumn{4}{|l|}{ Non-Clinical trial PrEP research } \\
\hline $\mathrm{MSM}^{\mathrm{a}}$ & US & 10 & 9 \\
\hline MSM & UK, Canada, France, Australia & 5 & 5 \\
\hline $\mathrm{MSM}^{\mathrm{b}}$ & China, Thailand, Peru & 4 & 4 \\
\hline $\begin{array}{l}\text { Serodiscordant Couples (SDC) } \\
\text { MSM and Transgender (TG) }\end{array}$ & Multi-country studies & 1 & 1 \\
\hline Heterosexual men and women ${ }^{c}$ & US & 2 & 2 \\
\hline Total & & 22 & 21 \\
\hline
\end{tabular}

MSM in Australia were sceptical that TasP could reduce onward transmission risks, although HIV-positive participants were less sceptical than HIV-negative participants.

\section{Risk Compensation and Disinhibition}

Much of the research addressed the use of condoms and sexual risk behaviour in combination with PrEP or TasP in some capacity. Where reported, studies embedded in RCTs described ongoing or even increased condom use in combination with PrEP use amongst participants [38]. Outside clinical trials, where PrEP was not yet available, studies could only investigate hypothetical condom use and two with MSM found that significant numbers of participants predicted decreased condom use if PrEP were to be taken [47, 63]. However, other studies with MSM predicted a minimal decrease in condom use [48, 58, 62]. One study described conflicting concerns amongst MSM that PrEP could encourage UAI or could provide an additional safety measure if condoms were not used [52]. One of the TasP studies reported how participants took viral load into account in relation to sexual risk and that having a low viral load was associated with recent STI acquisition [68]. The authors suggested that beliefs around infectiousness and increased risk of STI acquisition need to be addressed.

Few of the studies explored if, or how, participants thought they were at risk. Four studies explicitly asked about self-perceptions of risk [49, 53, 58, 65]. Of these, all but one found most participants did not perceive themselves to be at high risk of HIV [53]. Studies that included participants in serodiscordant relationships did not explicitly explore perceptions of risk. Brooks et al. [46] did explore how serodiscordant MSM couples managed risk and found that most relied on condoms, although strategic positioning and withdrawal were also reported. Golub et al. [48] reported that PrEP could reduce perceptions of HIV risk amongst MSM who would see unprotected sex as an acceptable risk in the context of PrEP (risk compensation), but also reduce the behavioural constraints for men who desire condomless sex (behavioural disinhibition). This distinction between compensation and disinhibition was only explored within a few studies. In addition, both Golub et al. [48] and Holt et al. [58] found that some MSM who reported non-condom use and high risk sexual behaviour also indicated a willingness to use PrEP. The authors concluded that non-condom use for these men may not be risk compensation (the replacement of condoms with PrEP); PrEP use would instead signal an increase in response to risk of HIV because condoms were never or rarely used.

\section{Social and Structural Issues}

Social and structural influences on adherence or willingness were only considered by seven studies. Amico et al. [70] demonstrated how social desirability to be an adherent trial participant may play in both the reporting and management of PrEP adherence. Ware et al. [39] described how the social context, especially in relation to intimate and/or marital relationships, was integral to adherence as well as to how HIV risk management is negotiated on a personal, intra-personal and socio-cultural level. Looking to a broader social context, Galindo et al. [53] reported on the importance of awareness and understanding of PrEP within communities and the need to address mistrust of medical settings. Guest et al. [38] found that in addition to individual counselling, structural constraints such as financial concerns, access to health services and HIV-related social 
stigma needed to be considered when assessing and responding to adherence challenges. Similarly, Galea et al. [63] identified structural barriers to PrEP access and adherence, such as cost of PrEP, mistrust of health providers and discrimination in relation to PrEP use. Where Smith et al. [66] reported on the importance of low cost in relation to willingness, and Galindo et al. [53] reported cost as a significant barrier, Eisingerich et al. [64] found that cost itself was not always a barrier as participants were willing to pay for PrEP.

\section{Discussion}

This review found that acceptability research in relation to PrEP and TasP was highly unbalanced in terms of population, geographic diversity, and research context. Notably, we found only three TasP acceptability studies and PrEP acceptability research which focused primarily on MSM in a US context. We also found varied accounts of acceptability and little reporting or consistency of how interventions were presented to participants. While levels of willingness to use PrEP were high amongst the majority of study participants, little attention was given to the importance of risk perception, as well as to how social and structural influences would impact PrEP or TasP acceptability. Our findings have important implications for future research, intervention implementation and scale-up. First, we will discuss the limitations of this study.

We considered only peer review published studies. Although a number of research gaps have been identified, this is a fast moving field and the review may have missed other studies have not yet been published in peer review journals. We did not conduct a critical appraisal of study quality. However, the aim of the study was to gain a broad overview of the research available, rather than assess the quality. Finally, this review focused primarily on research relating to oral PrEP. Literature on the use of microbicides was not explored and may have produced different evidence on awareness, willingness and acceptability with different populations.

The sheer lack of TasP acceptability research demonstrates that it has been framed primarily as a clinical and health service delivery issue and tacitly assumes that people living with HIV will accept early treatment as an inevitability. Chen [26] reviewed research that explored the impact of treatment-related optimistic beliefs and risk of HIV transmission. However, this review focuses largely on the understandings of science and potential for risk compensation, rather than on the acceptability of using ARVs as a clinically-endorsed HIV prevention intervention at the point of diagnosis. Therefore, how people living with HIV might negotiate both their epidemiological and social role in HIV prevention, what additional burdens this might place on their physical and mental health, and how TasP as an intervention may play a role in reinforcing or refocusing social stigma around HIV onto the positive body is largely absent from the current scientific evidence.

The majority of PrEP research within trials focused on heterosexual women in serodiscordant couples, while most stand-alone studies concentrated almost exclusively on MSM. There were only two studies which included heterosexual men. It is noteworthy that willingness to use PrEP was reported to be high among MSM, suggesting it could be a popular HIV prevention method within this population. However, it is unclear why this may be the case. Knowledge and willingness in some studies were associated with education and age, but there were no overall consistent findings across studies. Age may still be an important factor to explore, although it is unclear whether there may be a generational effect. Future research should consider how knowledge of and/or previous experiences with HIV, particularly in relation to PEP [55], could influence PrEP use. Most studies were conducted in the US, and there was only one published articled on PrEP acceptability in the UK with any population at the time of the review. While there is research underway to address the imbalance, this has implications for considering where, and for whom, ARVs might offer a potential HIV prevention option.

This review found highly varied measures of acceptability, which makes it difficult to compare results across studies. This variation is supported by findings from Mensch et al. [35] who highlight that there is little consensus on the definition and operationalisation of acceptability for PrEP. However, different approaches to acceptability did not appear to affect the overall results in this review: the majority of studies reported high rates of willingness to use PrEP, regardless of whether participants were presented with a single willingness question, multiple questions or a range of PrEP scenarios. This suggests the need to further consider who is being asked about acceptability, how they respond to these questions and what motivates these responses. For instance, motivation to take or maintain adherence to PrEP may be affected by serodiscordant relationships [39] or engagement in high-risk sexual activity [48]. Questions about acceptability therefore need to push beyond simple willingness, to understand the context within which interventions such as PrEP might be acceptable and/or preferred. Only five studies provided specific information, including efficacy rates, for PrEP, whereas most did not specify these rates or did not report this. Two articles described how this information, and the way interventions are framed, will have significant implications for the acceptability and uptake of these interventions [53, 66]. Transparency and consistency in terms of how PrEP and TasP are presented to participants is 
therefore critical to understanding if, and in what circumstances, these interventions will be acceptable to potential users, and how they might or might not be used in combination with other prevention options. This will also require consideration of the environment in which PrEP and/or TasP are offered to potential users, including the acceptability of these interventions to health practitioners [71].

Acceptability was generally approached and assessed by considering: willingness to take PrEP or TasP; adherence to PrEP (or TasP); and subsequent or hypothetical risk compensation and/or disinhibition. These approaches focus on the ways in which the individual chooses and/or manages the use of the intervention and their sexual behaviour (hence their description as bio-behavioural) [32]. Although important, willingness or adherence alone will not necessarily translate into sustained and effective use of interventions; it is also critical to consider how individuals' choices and actions are situated, constrained and/or enabled by the broader social context [4]. There was limited evidence of this in our review. Kippax and Stephenson [5] have argued not only that the broader social context needs to be considered, but that using ARVs for HIV prevention will necessarily require understanding and responding to the social context within which they might be used, describing the need for a social public health approach. In other words, the way in which individuals view, choose, and maintain the use of particular HIV prevention methods are significantly influenced by social, cultural and structural factors. Moreover, the social context within which negotiations of safer sex take place will also have a real impact on how interventions are sustained, and how sexual behaviour may be modified in light of these new prevention methods. This means that measurements of acceptability will need to move beyond expressions of willingness or adherence to medication, and consider the broader social, cultural and structural factors that will impact and shape the potential uptake and sustained effectiveness of PrEP and/or TasP. While the evidence is limited in this review, key factors include but are not limited to: social stigma, social pressures regarding sexual relationships, mistrust of medical settings and structural constraints including financial barriers and access.

Perceptions of risk and choice of risk management strategy appear to be key factors in adherence to PrEP [72]. However, risk perception and existing risk management by participants were discussed in a minority of articles in our review. As highlighted by Golub et al. [33] behavioural disinhibition and risk compensation present important differences in perceptions of risk and reasons for the choice and/or apparent absence of particular HIV risk management strategies. More nuanced understandings of risk management, including how multiple and conflicting risks might be managed, are therefore needed to better understand in what circumstances PrEP may be an appropriate intervention. In a community report which explored the experiences of black Africans in serodiscordant relationships living in the UK, Bourne et al. [73] described HIV positive-women's anxieties that TasP might reduce their ability to negotiate condom use with discordant, male partners. These women were reluctant to rely on TasP as a prevention option, thus demonstrating how gender dynamics in serodiscordant relationships can play an important role in risk management strategies for HIVpositive women. These issues highlight how complicated social negotiations are embedded in starting and maintaining adherence to ARV prevention methods. Future acceptability research needs to consider the way in which diverse social contexts will play a significant role in the success of PrEP or TasP.

There was also limited evidence of the role structural factors may play in the acceptability of biomedical prevention. The studies that examined this suggested future trial design and decisions about the introduction of biomedical prevention into sexual health services need to be realistic about where adherence to PrEP is possible for individuals and where more structural approaches to HIV prevention may need to be pursued [38]. The need to identify the causes of poor adherence was stressed. If social structures form the biggest barriers to adherence, individual counselling and support will be unable to improve adherence rates. In addition, barriers such as access to health services or the cost of interventions were identified as playing an important role in the uptake of interventions. However, the variation across studies in terms of national and local health systems, and the extent to which cost was identified as a barrier, makes it difficult to offer general conclusions. This suggests the need to consider social and structural elements specific to national and local contexts. These findings echo Roberts and Matthews [74] who argue for the importance of structural HIV prevention interventions alongside biomedical and behavioural interventions.

\section{Conclusions}

Literature on the acceptability of ARV prevention interventions amongst potential users focused largely on MSM (and to a lesser extent, heterosexual women in Africa), and was strikingly limited when it came to TasP. In order to strengthen understandings of how PrEP and/or TasP might be introduced and maintained as sustainable and effective HIV prevention interventions, further research is needed in five areas: engagement with people living with HIV in relation to potential TasP acceptability as well as perceptions of existing experiences with ARVs; further 
operationalisation of measures of acceptability to enable comparison between future studies and which move beyond measurements of adherence alone; further examination of what might motivate individuals to take PrEP, moving beyond categories such as age and education; the role of existing, complex (behavioural) risk management strategies in the adoption of biomedical prevention; and the potential role of social and structural influences above and beyond individual choices and/or behaviours, which would include examining the role of health providers in PrEP uptake and support. These five broad areas of research would help to further a social public health approach to acceptability and enable the identification of when, where and for whom ARVs for HIV prevention would be appropriate and effective. Our review suggests that, despite the issuing of guidelines for PrEP use in the US and the roll out of TasP at the clinical (if not the population) level, numerous questions remain as to just how acceptable, and therefore successful, these interventions will be in altering the course of the HIV epidemic. We have a responsibility to ensure that they are answered to achieve the true potential of biomedical HIV prevention.

Acknowledgments Funded by the UK Medical Research Council as part of the Sexual Health programme (MC_A540_5TK60) at the MRC/CSO Social and Public Health Sciences Unit, University of Glasgow. Thanks to Candida Fenton, the Unit's Information Scientist, who conducted the original literature searches for the review.

Open Access This article is distributed under the terms of the Creative Commons Attribution License which permits any use, distribution, and reproduction in any medium, provided the original author(s) and the source are credited.

\section{References}

1. Padian NS, Buve A, Balkus J, Serwadda D, Cates W Jr. Biomedical interventions to prevent HIV infection: evidence, challenges, and way forward. Lancet. 2008;372(9638):585-99.

2. Sturt Amy S, Dokubo Emily K, Sint Tin T. Antiretroviral therapy (ART) for treating HIV infection in ART-eligible pregnant women. Cochrane Database of Systematic Reviews. 2010. http://onlinelibrary. wiley.com/doi/10.1002/14651858.CD008440/abstract. Accessed 2 Oct 2012.

3. Rey D. Post-exposure prophylaxis for HIV infection. Expert Rev Anti Infect Ther. 2011;9(4):431-42.

4. Kippax S, Race K. Sustaining safe practice: twenty years on. Soc Sci Med. 2003;57(1):1-12.

5. Kippax S, Stephenson N. Beyond the distinction between biomedical and social dimensions of HIV prevention through the lens of a social public health. Am J Public Health. 2012;102(5):789-99.

6. Havlir D, Beyrer C. The beginning of the end of AIDS? N Engl J Med. 2012;367(8):685-7.

7. Anderson PL, Glidden DV, Liu A, et al. Emtricitabine-tenofovir concentrations and pre-exposure prophylaxis efficacy in men who have sex with men. Sci Transl Med. 2012;4(151):1-8.

8. Okwundu CI, Uthman OA, Okoromah CA. Antiretroviral pre-exposure prophylaxis (PrEP) for preventing HIV in high-risk individuals. Cochrane Database Syst Rev. 2012. http://onlinelibrary.wiley.
com/doi/10.1002/14651858.CD007189.pub3/abstract. Accessed 2 Oct 2012.

9. Food and Drug Administration (FDA). FDA approves first drug for reducing the risk of sexually acquired HIV infection. Silver Spring, MD: FDA. 2012. http://www.fda.gov/NewsEvents/Newsroom/ PressAnnouncements/ucm312210.htm. Accessed 2 Oct 2012.

10. Center for Disease Control (CDC). Interim guidance: Pre-exposure prophylaxis for the prevention of HIV infection in men who have sex with men. Morbidity and Mortality Weekly Report. 2011;60(3):65-8.

11. Center for Disease Control (CDC). Interim guidance: pre-exposure prophylaxis for the prevention of HIV infection in heterosexually active adults. Morbidity and Mortality Weekly Report. 2012;61(31):586-9.

12. Rossi L. Daily HIV prevention approaches didn't work for African women in the VOICE study. Atlanta: MTN: Microbicides Trials Network. 2013. http://www.mtnstopshiv.org/sites/default/ files/attachments/MTN_VOICE_Release_FINAL_.pdf. Accessed 8 May 2013.

13. ECDC. Thematic report: HIV treatment, care and support: monitoring implementation of the Dublin Declaration on partnership to fight HIV/AIDS in Europe and central Asia: 2012 progress report. Stockholm: European Centre for Disease and Prevention Control. 2013

14. McCormack S, Fidler S, Fischer M. The British HIV Association/ British Association for Sexual Health and HIV position statement on pre-exposure prophylaxis in the UK. Int J STD AIDS. 2012;23(1):1-4.

15. European Medicines Agency (EMA). Reflection paper on the non-clinical and clinical development for oral and topical HIV pre-exposure prophylaxis (PrEP). London: EMA. 2012. http:// www.ema.europa.eu/docs/en_GB/document_library/Scientific_ guideline/2012/03/WC500124054.pdf. Accessed 2 Oct 2012.

16. Cohen MS, McCauley M, Gamble TR. HIV treatment as prevention and HPTN 052. Curr Opin HIV AIDS. 2012;7(2):99-105.

17. BHIVA. BHIVA guidelines for the treatment of HIV-1 positive adults with antiretroviral therapy 2012. London: British HIV Association; 2012.

18. Panel on Antiretroviral Guidelines for Adults and Adolescents. Guidelines for the use of antiretroviral agents in HIV-1-infected adults and adolescents: Department of Health and Human Services, Office of AIDS Research Advisory Council (OARAC).

19. WHO. 2013. WHO issues new HIV recommendations calling for earlier treatment. World Health Organisation. http://www.who. int/mediacentre/news/releases/2013/new_hiv_recommendations_ 20130630/en/index.html. Accessed 1 July 2013.

20. BHIVA, EAGA. Position statement on the use of antiretroviral therapy to reduce HIV transmission January 2013, British HIV Association (BHIVA) and the Expert Advisory Group on AIDS (EAGA). HIV Med. 2013;14(5):259-62.

21. Williams BG, Lima V, Gouws E. Modelling the impact of antiretroviral therapy on the epidemic of HIV. Curr HIV Res. 2011; 9(6):367-82.

22. van de Laar MJ, Pharris A. Treatment as prevention: will it work? Euro Surveillance. 2011;16(48):1-3.

23. Nguyen VK, Bajos N, Dubois-Arber F, O’Malley J, Pirkle CM. Remedicalizing an epidemic: from HIV treatment as prevention to HIV treatment is prevention. AIDS. 2011;25(3):291-3.

24. International Collaboration on HIV Optimism. HIV treatments optimism among gay men: an international perspective. J Acquir Immune Defic Syndr. 2003;32(5):545-50.

25. Crepaz N, Hart TA, Marks G. Highly active antiretroviral therapy and sexual risk behavior: a meta-analytic review. JAMA. 2004; 292(2):224-36.

26. Chen Y. Treatment-related optimistic beliefs and risk of HIV transmission: a review of recent findings (2009-2012) in an era of treatment as prevention. Curr HIV/AIDS Rep. 2013;10(1):79-88. 
27. Vernazza PL. The debate continues: does 'undetectable' mean 'uninfectious'? HIV Ther. 2009;3(2):113-6.

28. Rojas Castro D, Fugon L, Bourgeois-Fisson E, Le Gall JM, Barbier F, Spire B. The "Swiss Statement": Who knows about it? How do they know? What are its effects on people living with HIV/AIDS? AIDS Care. 2012;24(8):1013-9.

29. Persson A. Reflections on the Swiss Consensus Statement in the context of qualitative interviews with heterosexuals living with HIV. AIDS Care. 2010;22(12):1487-92.

30. de Wit JBF, Aggleton P, Myers T, Crewe M. The rapidly changing paradigm of HIV prevention: time to strengthen social and behavioural approaches. Health Educ Res. 2011;26(3): 381-92.

31. Diallo DD. 2013. Coalition of U.S. Women's health and HIV advocates call for accelerated us government plan for demonstrating feasibility of PrEP for women. Working Group on U.S. Women and PrEP. http://www.avac.org/ht/a/GetDocumentAction/i/ 49158. Accessed 1 July 2013.

32. Amico KR. Adherence to pre-exposure chemoprophylaxis: the behavioral bridge from efficacy to effectiveness. Curr Opin HIV AIDS. 2012;7(6):542-8.

33. Golub SA, Operario D, Gorbach PM. Pre-exposure prophylaxis state of the science: empirical analogies for research and implementation. Curr HIV/AIDS Rep. 2010;7(4):201-9.

34. Severy LJ, Newcomer S. Critical issues in contraceptive and STI acceptability research. J Soc Issues. 2005;61(1):45-65.

35. Mensch BS, van der Straten A, Katzen LL. Acceptability in microbicide and PrEP trials: current status and a reconceptualization. Curr Opin HIV AIDS. 2012;7(6):534-41.

36. von Elm E, Altman DG, Egger M, Pocock SJ, Gøtzsche PC. The strengthening the reporting of observational studies in epidemiology (STROBE) statement: guidelines for reporting observational studies. PLoS Med. 2007;4(10):e296.

37. Guest G, Shattuck D, Johnson L, et al. Changes in sexual risk behavior among participants in a PrEP HIV prevention trial. Sex Transm Infect. 2008;35(12):1002-8.

38. Guest G, Shattuck D, Johnson L, et al. Acceptability of PrEP for HIV prevention among women at high risk for HIV. J Womens Health. 2010;19(4):791-8.

39. Ware NC, Wyatt MA, Haberer JE, et al. What's love got to do with it? Explaining adherence to oral antiretroviral pre-exposure prophylaxis for HIV-serodiscordant couples. J Acquir Immune Defic Syndr. 2012;59(5):463-8.

40. Minnis AM, Gandham S, Richardson BA, et al. Adherence and acceptability in MTN 001: a randomized cross-over trial of daily oral and topical tenofovir for HIV prevention in women. AIDS Behav. 2013;17(2):737-47.

41. Mutua G, Sanders E, Mugo P, et al. Safety and adherence to intermittent pre-exposure prophylaxis (PrEP) for HIV-1 in African men who have sex with men and female sex workers. PLoS One. 2012;7(4):e33103.

42. Van der Elst EM, Mbogua J, Operario D, et al. High acceptability of HIV pre-exposure prophylaxis but challenges in adherence and use: qualitative insights from a phase I trial of intermittent and daily PrEP in at-risk populations in Kenya. AIDS Behav. 2013;17(6):2162-72.

43. Hosek S, Siberry G, Bell M, et al. The acceptability and feasibility of an HIV pre-exposure prophylaxis (PrEP) trial with young men who have sex with men (YMSM). J Acquir Immune Defic Syndr. 2012;62(4):447-56.

44. Amico KR, McMahan V, Goicochea P, et al. Supporting study product use and accuracy in self-report in the iPrEx study: next step counseling and neutral assessment. AIDS and Behavior. 2012;16(5):1243-59.

45. Barash EA, Golden M. Awareness and use of HIV pre-exposure prophylaxis among attendees of a Seattle gay pride event and sexually transmitted disease clinic. AIDS Patient Care STDs. 2010;24(11):689-91.

46. Brooks RA, Kaplan RL, Lieber E, Landovitz RJ, Lee SJ, Leibowitz AA. Motivators, concerns, and barriers to adoption of preexposure prophylaxis for HIV prevention among gay and bisexual men in HIV-serodiscordant male relationships. AIDS Care. 2011;23(9):1136-45.

47. Brooks RA, Landovitz RJ, Kaplan RL, Lieber E, Lee SJ, Barkley TW. Sexual risk behaviors and acceptability of HIV pre-exposure prophylaxis among HIV-negative gay and bisexual men in serodiscordant relationships: a mixed methods study. AIDS Patient Care STDs. 2012;26(2):87-94.

48. Golub SA, Kowalczyk W, Weinberger CL, Parsons JT. Preexposure prophylaxis and predicted condom use among high-risk men who have sex with men. J AIDS. 2010;54(5):548-55.

49. Krakower DS, Mimiaga MJ, Rosenberger JG, et al. Limited awareness and low immediate uptake of pre-exposure prophylaxis among men who have sex with men using an internet social networking site. PLoS One. 2012;7(3):e33119.

50. Mansergh G, Koblin BA, Colfax GN, McKirnan DJ, Flores SA, Hudson SM. Preefficacy use and sharing of antiretroviral medications to prevent sexually-transmitted HIV infection among us men who have sex with men. J AIDS. 2010;55(2):e14-6.

51. Mimiaga MJ, Case P, Johnson CV, Safren SA, Mayer KH. Preexposure antiretroviral prophylaxis attitudes in high-risk Boston area men who report having sex with men: limited knowledge and experience but potential for increased utilization after education. J Acquir Immune Defic Syndr. 2009;50(1):77-83.

52. Nodin N, Carballo-Dieguez A, Ventuneac AM, Balan IC, Remien R. Knowledge and acceptability of alternative HIV prevention bio-medical products among MSM who bareback. AIDS Care. 2008;20(1):106-15.

53. Galindo GR, Walker JJ, Hazelton P, et al. Community member perspectives from transgender women and men who have sex with men on pre-exposure prophylaxis as an HIV prevention strategy: implications for implementation. Implement Sci. 2012;7(1):116.

54. Saberi P, Gamarel KE, Neilands TB, et al. Ambiguity, ambivalence, and apprehensions of taking HIV-1 pre-exposure prophylaxis among male couples in San Francisco: a mixed methods study. PLoS One. 2012;7(11):e50061.

55. Aghaizu A, Mercey D, Copas A, Johnson AM, Hart G, Nardone A. Who would use PrEP? Factors associated with intention to use among MSM in London: a community survey. Sex Transm Infect. 2013;89(3):207-11.

56. Leonardi M, Lee E, Tan DH. Awareness of, usage of and willingness to use HIV pre-exposure prophylaxis among men in downtown Toronto, Canada. Int J STD AIDS. 2011;22(12): $738-41$.

57. Lorente N, Fugon L, Carrieri MP, et al. Acceptability of an "ondemand" pre-exposure HIV prophylaxis trial among men who have sex with men living in France. AIDS Care. 2012;24(24): 468-77.

58. Holt M, Murphy DA, Callander D, et al. Willingness to use HIV pre-exposure prophylaxis and the likelihood of decreased condom use are both associated with unprotected anal intercourse and the perceived likelihood of becoming HIV positive among Australian gay and bisexual men. Sex Transm Infect. 2012;88(4):258-63.

59. Poynten IM, Jin F, Prestage GP, Kaldor JM, Imrie J, Grulich AE. Attitudes towards new HIV biomedical prevention technologies among a cohort of HIV-negative gay men in Sydney, Australia. HIV Med. 2010;11(4):282-8.

60. van Griensven F, Thienkrua W, Sukwicha W, et al. Sex frequency and sex planning among men who have sex with men in Bangkok, Thailand: implications for pre- and post-exposure prophylaxis against HIV infection. J Int AIDS Soc. 2010;13(13):1-14. 
61. Jackson T, Huang A, Chen H, Gao X, Zhong X, Zhang Y. Cognitive, psychosocial, and sociodemographic predictors of willingness to use HIV pre-exposure prophylaxis among Chinese men who have sex with men. AIDS Behav. 2012;16(7):1853-61.

62. Zhou F, Gao L, Li S, et al. Willingness to accept HIV preexposure prophylaxis among Chinese men who have sex with men. PLoS One. 2012;7(3):e32329.

63. Galea JT, Kinsler JJ, Salazar X, et al. Acceptability of preexposure prophylaxis as an HIV prevention strategy: Barriers and facilitators to pre-exposure prophylaxis uptake among at-risk Peruvian populations. Int J STD AIDS. 2011;22(5):256-62.

64. Eisingerich AB, Wheelock A, Gomez GB, Garnett GP, Dybul MR, Piot PK. Attitudes and acceptance of oral and parenteral HIV preexposure prophylaxis among potential user groups: a multinational study. PLoS One. 2012;7(1):e28238.

65. Whiteside YO, Harris T, Scanlon C, Clarkson S, Duffus W. Self-perceived risk of HIV infection and attitudes about preexposure prophylaxis among sexually transmitted disease clinic attendees in South Carolina. AIDS Patient Care STDs. 2011; 25(6):365-70.

66. Smith DK, Toledo L, Smith DJ, Adams MA, Rothenberg R. Attitudes and program preferences of African-American urban young adults about pre-exposure prophylaxis (PrEP). AIDS Educ Prev. 2012;24(5):408-21.

67. Dombrowski JC, Harrington RD, Fleming M, Golden MR. Treatment as prevention: are HIV clinic patients interested in starting antiretroviral therapy to decrease HIV transmission? AIDS Patient Care STDs. 2010;24(12):747-50.

68. Kalichman SC, Eaton L, Cherry C. Sexually transmitted infections and infectiousness beliefs among people living with HIV/ AIDS: implications for HIV treatment as prevention. HIV Med. 2010;11(8):502-9.

69. Holt M, Murphy D, Callander D, et al. HIV-negative and HIVpositive gay men's attitudes to medicines, HIV treatments and antiretroviral-based prevention. AIDS Behav. 2012;17(6):2156-61.

70. Amico K, McMahan V, Goicochea P, et al. Supporting study product use and accuracy in self-report in the iPrEx study: next step counseling and neutral assessment. AIDS Behav. 2012;16(5):1243-59.

71. Puro V, Palummieri A, de Carli G, Piselli P, Ippolito G. Attitudes towards antiretroviral pre-exposure prophylaxis $(\mathrm{PrEP})$ prescription among HIV specialists. BMC Infect Dis. 2013;13(217):1-8.

72. Mascolini M. Tenofovir PrEP reduces HIV transmission risk by up to $99 \%$ : adherence critical to protection from HIV in partners PrEP trial of TDF and TDF/FTC 19th Conference on Retroviruses and Opportunistic Infections. Washington: Seattle; 2012.

73. Bourne A, Dodds C, Weatherburn P, et al. Plus one: HIV serodiscordant relationships among black African people in England. London: Sigma Research; 2011.

74. Roberts ET, Matthews DD. HIV and chemoprophylaxis, the importance of considering social structures alongside biomedical and behavioral intervention. Soc Sci Med. 2012;75(9):1555-61. 